\title{
Diverging Diamond Interchange
}

\author{
Ashis Kumar Sarangi \\ Department Of Civil Engineering Institute Of Technical Education And Research Siksha 'O' Anusandhan \\ University Bhubaneswar, Odisha, India
}

\begin{abstract}
Transport system and roads always plays vital role in the development of a city. With virtue of this, TranSystems has been at the forefront for the development and design of Diverging Diamond Network with an option of several open to traffic and number of others under design consideration. There are various considerations for when to choose a DDI and how to prepare an effective design. Considerations like assessing whether it would be very effective under existing conditions, crossover design strategies, pedestrian accommodations, right turn issues, traffic signal operation. DDI can be a very cost effective solutions in retrofit situations due to ability to work with existing bridge structure. DDI proved to be very effective in a situation where majority of the crossroad traffic is approaching or going to the freeway and also proved to be effective in traffic on cross road. Thus it had proved effective in reducing traffic volumes and enhancing quality of accessibility to a larger extent in the present scenario. The project will henceforth provide an overview of various elements of DDI and its design considerations taken into account.
\end{abstract}

Design Problem statement

\section{Introduction}

Design of a Diverging Diamond Interchange Network at Chandikhole (Odisha)

\section{Interchange Redesign Concept}

\begin{tabular}{|c|c|c|c|c|c|}
\hline Flyo & Ramp & $\begin{array}{ll}\text { Outer } & \\
\text { Connection } \quad \text { Ramp }\end{array}$ & $\begin{array}{ll}\text { Direct } & \text { Con } \\
\text { Ramp } & \\
\end{array}$ & Lane & oop \\
\hline $\begin{array}{l}\text { A flyover crosses } \\
\text { over another road } \\
\text { allowing vehicles } \\
\text { to cross through } \\
\text { it to facilitate } \\
\text { traffic } \\
\text { movements from } \\
\text { one part to other. }\end{array}$ & $\begin{array}{l}\text { An } \\
\text { interconnecting } \\
\text { roadway of a } \\
\text { traffic interchange } \\
\text { on which a traffic } \\
\text { may enter or leave } \\
\text { a designated } \\
\text { roadway. }\end{array}$ & $\begin{array}{l}\text { A ramp used by } \\
\text { traffic designated } \\
\text { for left turn } \\
\text { movements from } \\
\text { one of the roadways } \\
\text { through it separated } \\
\text { by a grade through } \\
\text { roadway. }\end{array}$ & $\begin{array}{l}\text { A ramp which does } \\
\text { not deviate much } \\
\text { from the intended } \\
\text { direction. It avoids } \\
\text { the loop for right } \\
\text { turning movement. } \\
\text { It is the direct } \\
\text { connection ramp for } \\
\text { left turning. }\end{array}$ & $\begin{array}{l}\text { Acceleration lane/ } \\
\text { Deacceleration lane } \\
\text { An acceleration lane enable } \\
\text { a vehicle entering a road to } \\
\text { increase its speed. } \\
\text { A deacceleration lane } \\
\text { enable a vehicle leaving } \\
\text { though traffic to decrease its } \\
\text { speed. }\end{array}$ & $\begin{array}{l}\text { A one way } \\
\text { turning } \\
\text { roadway that } \\
\text { curves about } \\
270 \text { degree to } \\
\text { the left to } \\
\text { accommodate } \\
\text { a right turning } \\
\text { movement. }\end{array}$ \\
\hline
\end{tabular}

\section{Function decomposition}

Function tree by subtract and operate procedure

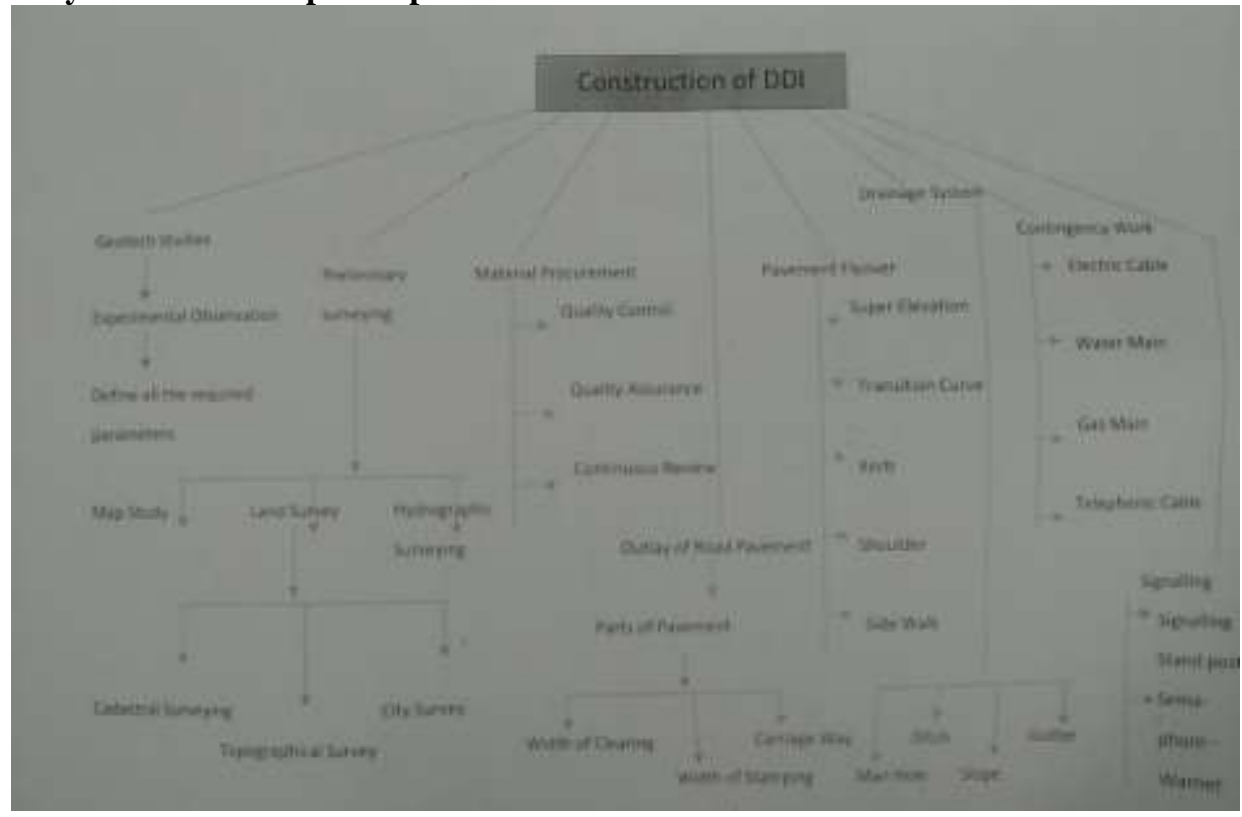


Product metric model

Model selection by performance specifications

\begin{tabular}{|l|l|}
\hline Completely New Network & Modification On The Existing Network \\
\hline $\begin{array}{l}\text { The figure shows the completely new construction of the } \\
\text { diamond diverging network system. }\end{array}$ & $\begin{array}{l}\text { The modified fig shows that without being constructing the new } \\
\text { network we can modify the network to convert it to a diamond } \\
\text { diverging network system }\end{array}$ \\
\hline $\begin{array}{l}\text { It will not be cost effective because we can create } \\
\text { The network by modify it. Unnecessary Preliminary survey } \\
\text { will be required. }\end{array}$ & $\begin{array}{l}\text { It will be cost effective and the construction process will be finished } \\
\text { much sooner than the figure -1 }\end{array}$ \\
\hline Huge demolish of building will be required. & $\begin{array}{l}\text { Without being demolish of building the network construction can be } \\
\text { carried out. }\end{array}$ \\
\hline Provide bicyclist lane with three lane of the network & A separate lane is provide for the bicyclist. \\
\hline $\begin{array}{l}\text { Safety is less and more conflicting point which can reduce } \\
\text { the traffic safety }\end{array}$ & $\begin{array}{l}\text { Safety is more due to providence of the separate lane for bicyclist } \\
\text { and interconnected passage for people. }\end{array}$ \\
\hline No provision of the bus stop in that completely new model & Having the bus stop provision for the people. \\
\hline
\end{tabular}

\section{CONSTRUCTION SPECIFICATION}

ACTUAL SYSTEMMETRIC MODEL

6 lane network with median $=22 \mathrm{~m}$

NH 2 side lane with median $=15.4 \mathrm{~m}$

Point 3=kalinagar point to chandikhol chowk $=80 \mathrm{~m}$

Point 4=paradeep point to chandikhol chowk $=80 \mathrm{~m}$

Other 2way lane for turnout $7.5 \mathrm{~m}$

Height of the bridge $=8 \mathrm{~m}$

Point 1 to first diverging portion $=30 \mathrm{~m}$

Distance between the two turnout $=70 \mathrm{~m}$

Point 2 to second diverging portion $=30 \mathrm{~m}$

Point 1 to left turnout $=15 \mathrm{~m}$

Point 2 to left turnout $=20 \mathrm{~m}$
$16.5 \mathrm{~cm}$

$11.6 \mathrm{~cm}$

$60 \mathrm{~cm}$

$60 \mathrm{~cm}$

$6 \mathrm{~cm}$

$10 \mathrm{~cm}$

$14 \mathrm{~cm}$

$45 \mathrm{~cm}$

$14 \mathrm{~cm}$

$12 \mathrm{~cm}$

$15 \mathrm{~cm}$

II. Design And Layout

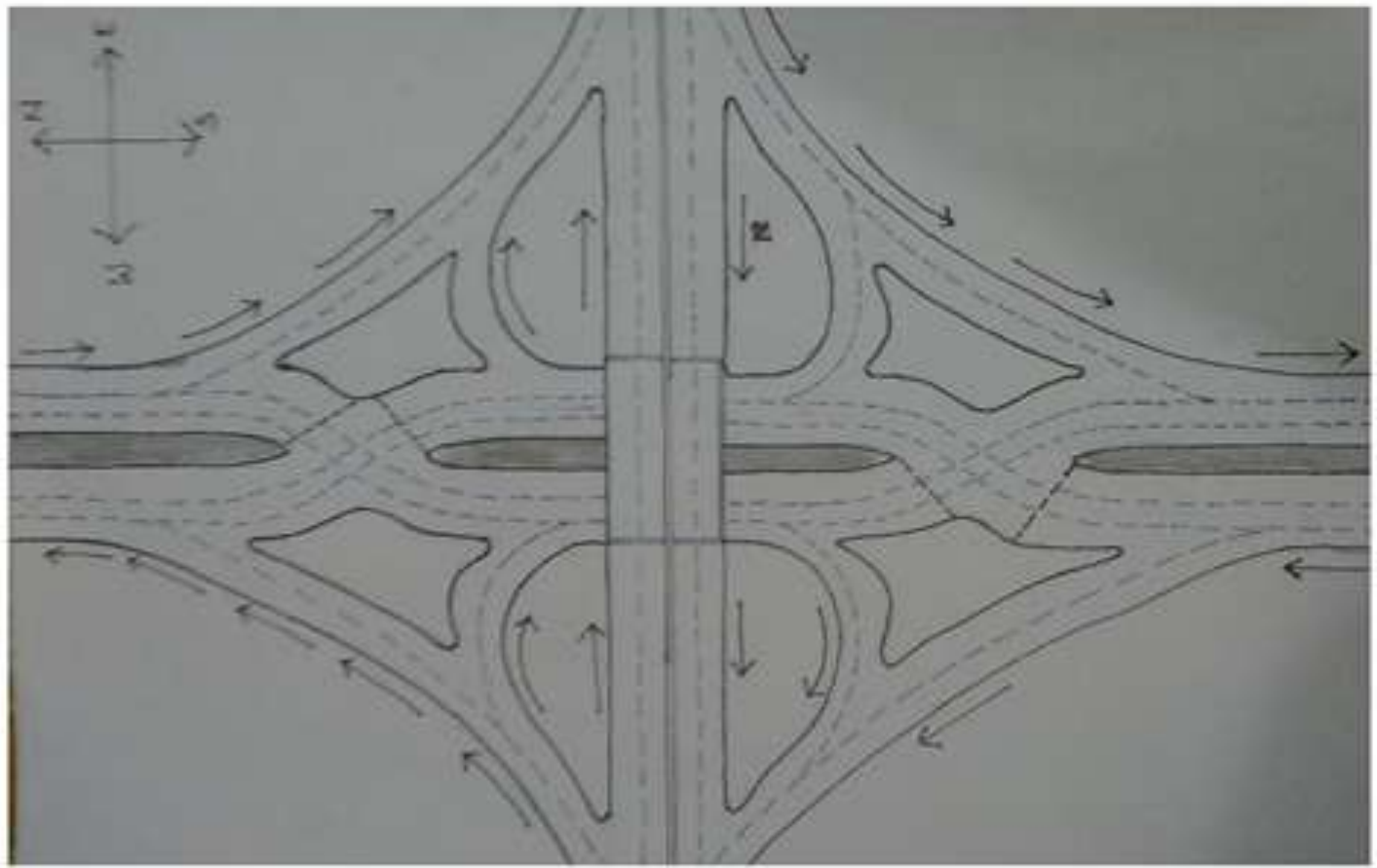

FIGURE -1 


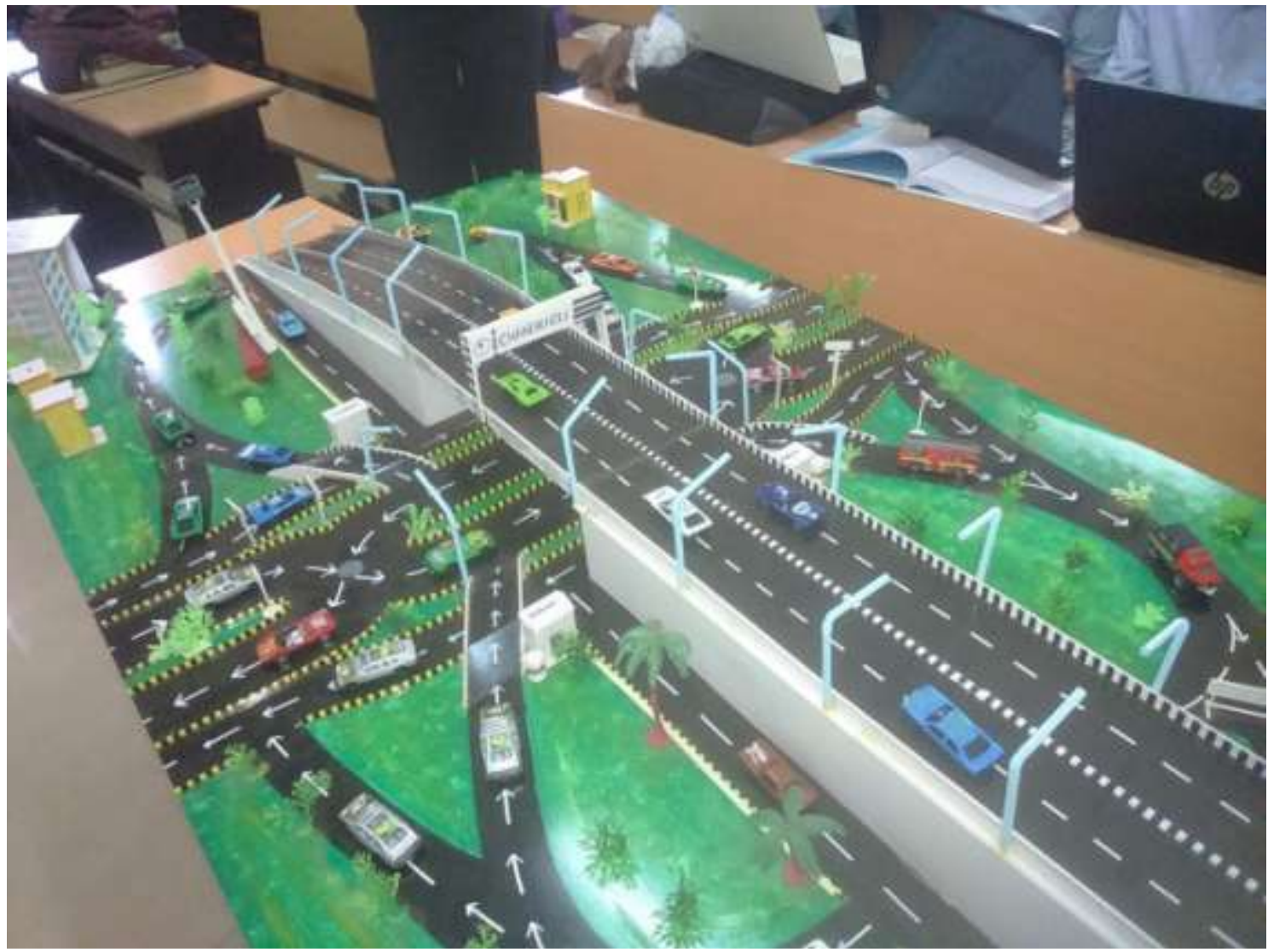

\section{Analytical and numerical model solutions}

Cross section elements

- Considering the Design Speed for the interchange to be $45 \mathrm{~km} / \mathrm{h}$ and minimum to be $30 \mathrm{~km} / \mathrm{h}$.

- Topography- Rolling Terrain

- Traffic Volume

Traffic volume in terms of number and PCU values ZONE 1 Flow Rate of One Hour (9am to 10am)

DIRECTION 1 CHANDIKHOL TO BHUBANESWAR
DIRECTION 2 BHUBANESWAR TO CHANDIKHOL
\begin{tabular}{|l|l|l|l|l|l|l|}
\hline Vehicle category & Direction 1 & Direction 2 & Total \\
\hline & Number & PCU & Number & PCU & Number & PCU \\
\hline Car//Van & 125 & 125 & 110 & 110 & 235 & 235 \\
\hline Mini Bus & 11 & 33 & 18 & 54 & 29 & 87 \\
\hline Bus & 23 & 69 & 28 & 84 & 51 & 153 \\
\hline 2 Wheeler & 120 & 60 & 98 & 49 & 218 & 109 \\
\hline Mini Truck & 68 & 204 & 50 & 150 & 118 & 354 \\
\hline Truck & 65 & 195 & 48 & 144 & 113 & 339 \\
\hline 3 Wheeler & 19 & 19 & 23 & 23 & 42 & 42 \\
\hline Cycle & 32 & 6 & 25 & 5 & 57 & 11 \\
\hline Total vehicles & 463 & 400 & & 863 & \\
\hline Total PCU & 711 & 619 & & 1330 & \\
\hline
\end{tabular}

AVERAGE TRAFFIC FLOWING IN ONE DIRECTION IS=1330/2 $=665$

$\mathrm{TV}=\mathrm{TOTAL}$ VOLUME $=\mathrm{PCU} * 4=665 * 4=2660$

TDV $=$ TOTAL 24 HOUR TRAFFIC $=2660 * 17.11=45512$

TOTAL 7 DAY TRAFFIC OBTAIN $=45512 * 7.012=319130$

AVERAGE TOTAL VOLUME $=319130 / 7=45590$

TOTAL YEAR VOLUME $=$ AADT $=45590 * 1.395=63598$ 
Traffic volume in terms of number and PCU values

ZONE -2 Flow Rate of One Hour (9am to 10am)

DIRECTION $1=$ CHANDIKHOL TO BHUBANESWAR

DIRECTION 2=BHUBANESWAR TO CHANDIKHOL

\begin{tabular}{|l|l|l|l|l|l|l|}
\hline Vehicle category & Direction 1 & Direction 2 & \multicolumn{2}{l|}{ Total } \\
\hline & Number & PCU & Number & PCU & Number & PCU \\
\hline Car//Van & 105 & 105 & 130 & 130 & 235 & 235 \\
\hline Mini Bus & 12 & 36 & 9 & 27 & 21 & 63 \\
\hline Bus & 18 & 54 & 21 & 63 & 39 & 117 \\
\hline 2 Wheeler & 82 & 41 & 112 & 56 & 194 & 97 \\
\hline Mini Truck & 75 & 225 & 58 & 174 & 133 & 399 \\
\hline Truck & 67 & 201 & 42 & 126 & 109 & 327 \\
\hline 3 Wheeler & 26 & 26 & 20 & 20 & 46 & 46 \\
\hline Cycle & 35 & 7 & 25 & 5 & 60 & 12 \\
\hline Total vehicles & 420 & $\mathbf{4 1 7}$ & & $\mathbf{8 3 7}$ & $\mathbf{1 2 9 6}$ \\
\hline Total PCU & 695 & $\mathbf{6 0 1}$ & & \\
\hline
\end{tabular}

\section{Cross slope or camber}

Camber provided $=2 \%$ i.e. 1 in 50 (Transverse slope is in ratio 1 vertical to 50 horizontal)

- Type of pavement surface- High bituminous surface

- Amount of rainfall- Moderate

Design of camber

As per IRC code Interchange carriageway with kerbs $=7.5 \mathrm{~m}$ (2 lanes)

For Bituminous surface,

Rise of crown with respect to the edges $=(7.5 / 2) *(1 / 50)=0.075 \mathrm{~m}$

Diagram of Combination of straight and parabolic shape

- $\quad$ Carriage way width $=7.5 \mathrm{~m}$

- Traffic separators of medians $=1.5 \mathrm{~m}$

- Total width of roadway which includes carriageway and other things $=15 \mathrm{~m}$

Sight distance

(a) Stopping Sight Distance

Calculating the safe stopping sight distance for design speed of $45 \mathrm{kmph}$ for two way traffic on a four lane road?

Assuming as per IRC coefficient of friction 0.37 and reaction time of driver $2.5 \mathrm{sec}$

Stopping distance $=$ lag distance + braking distance

$\mathrm{V}=45 \mathrm{kmph}$ or $\mathrm{v}=12.5 \mathrm{mps}$

$$
=\mathrm{vt}+\left(\mathrm{v}^{\wedge} 2 / 2 \mathrm{gf}\right)
$$

$\mathrm{t}=2.5 \mathrm{sec}, \mathrm{g}=9.8 \mathrm{~m} / \mathrm{s}^{\wedge} 2, \mathrm{f}=0.37$

Stopping distance $=12.5 * 2.5+\left(\left(12.5^{\wedge} 2\right) / 2 * 9.8 * 0.37\right)$

$=52.79 \mathrm{~m}$

- Stopping distance when there are two lanes= stopping distance $=52.79 \mathrm{~m}$

- Stopping distance for two way traffic when there are four lanes $=$ stopping distance $=2 * 52.79=105.58 \mathrm{~m}$

When the ground is not level, then the gradient or slope is to be taken into consideration.

Assuming the gradient to be 4 percent (As per IRC specification in interchange)

(i) For descending gradient of $4 \%$

$\mathrm{V}=45 \mathrm{kmph} ; \mathrm{n}=-4 \%=-0.04$

Stopping Distance $=0.278 \mathrm{vt}+\left(\left(\mathrm{v}^{\wedge} 2\right) / 254(\mathrm{f}-0.04)\right.$

$$
\begin{aligned}
& =0.278^{*} 12.5^{*} 2.5+\left(\left(45^{\wedge} 2\right) / 254(0.37-0.04)\right. \\
& =55.42 \mathrm{~m}
\end{aligned}
$$

(ii) For ascending gradient of $4 \%$

Stopping Distance $=0.278 \mathrm{vt}+\left(\left(\mathrm{v}^{\wedge} 2\right) / 254(\mathrm{f}+0.04)\right.$

$$
\begin{aligned}
& =0.278^{*} 12.5^{*} 2.5+\left(\left(45^{\wedge} 2\right) / 254(0.37+0.04)\right. \\
& =50.71 \mathrm{~m}
\end{aligned}
$$

(b) Overtaking Sight Distance

Design speed $=45 \mathrm{kmph}$

$\mathrm{V}=45 / 3.6=12.5 \mathrm{~m} / \mathrm{s}$

Considering the speed of overtaken vehicle $V_{b}=(12.5-4.5)=8 \mathrm{mps}$

From IRC code,

$\mathrm{A}=4.2 \mathrm{kmph} / \mathrm{sec}$

$\mathrm{t}=2.5 \mathrm{sec}$ 
$\mathrm{d}_{1}=0.28 \mathrm{~V}_{\mathrm{b}} \mathrm{t}$

where $\mathrm{d}_{1=}$ Distance travelled by overtaking vehicle A during the reaction time $\mathrm{t}$ seconds of driver from position

$\mathrm{A}_{1}$ to $\mathrm{A}_{2}$

$=0.28 * 29 * 2.5$

$=20.3 \mathrm{~m}$

$\mathrm{d}_{2}=0.28 \mathrm{~V}_{\mathrm{b}} \mathrm{T}+2 \mathrm{~s}$

where $d_{2}=$ Distance travelled by the vehicle $A$ from $A_{2}$ to $A_{3}$ during the actual overtaking operation, in time $T$ sec

$\mathrm{T}=$ sqrt. $(14.4 \mathrm{~s} / \mathrm{A})$

$\mathrm{s}=$ minimum spacing between 2 vehicles

$\mathrm{s}=\left(0.2 \mathrm{~V}_{\mathrm{b}}+6\right)$

$=(0.2 * 29+6)$

$=11.8 \mathrm{~m}$

$\mathrm{T}=$ sqrt. $((14.4 * 11.8) / 4.2)$

$=6.36 \mathrm{sec}$

$\mathrm{d}_{2}=0.28 * 29 * 6.36+2 * 11.8$

$=75.24 \mathrm{~m}$

$\mathrm{d}_{3}=0.28 \mathrm{VT}$

where $\mathrm{d}_{3}=$ Distance travelled by on-coming vehicle $\mathrm{C}$ from $\mathrm{C}_{1}$ to $\mathrm{C}_{2}$ during the overtaking operation of $\mathrm{A}$

$=0.28 * 45 * 6.36$

$=80.136 \mathrm{~m}$

OSD on one way traffic road $=\mathrm{d}_{1}+\mathrm{d}_{2}=20.3+75.24=95.54 \mathrm{~m}$

OSD on two way traffic road $=\mathrm{d}_{1}+\mathrm{d}_{2}+\mathrm{d}_{3}=20.3+75.24+80.136=175.67 \mathrm{~m}$

(c) Safe Sight distance

From IRC code for design speed $45 \mathrm{~km} / \mathrm{hr}$ will be $100 \mathrm{~m}$ (Approx.)

Horizontal Curves

When a vehicle traverses a horizontal curve, the centrifugal force acts horizontally outwards through the centre of gravity of the vehicle. Centrifugal force $\mathrm{P}$ is given by the equation:

$$
\mathrm{P}=\mathrm{Wv}^{2} / \mathrm{gR}
$$

Here $\mathrm{P}=$ Centrifugal force, $\mathrm{kg}$

$\mathrm{W}=$ weight of the vehicle, $\mathrm{kg}$

$\mathrm{R}=$ radius of circular curve, $\mathrm{m}$

$\mathrm{V}=$ speed of vehicle, $\mathrm{m} / \mathrm{sec}$

$\mathrm{g}=$ acceration due to gravity $=9.8 \mathrm{~m} / \mathrm{sec}^{2}$

As per IRC specification, minimum radius of horizontal curves for design speed of $45 \mathrm{kmph}$ may be taken as 90 $\mathrm{m}$ and absolute minimum radius for design speed of $30 \mathrm{kmph}$ may be $60 \mathrm{~m}$. It can be calculated from $R_{\text {ruling }}=V^{2} /$ $(127(e+f))$

Design of Superelevation

Step 1: The superelevation for $75 \%$ of design speed is calculated by neglecting the friction

$$
\begin{aligned}
\mathrm{e} & =\mathrm{V}^{2} / 225 \mathrm{R} \\
& =45^{2} /\left(225^{*} 90\right) \\
& =0.10
\end{aligned}
$$

Step 2: If the calculated value of e i.e. 0.10 is less than 0.07 , then the value is accepted. If not, then provide maximum superelevation equal to 0.07 .

Step 3: Check the co-efficient of friction

$$
\begin{aligned}
\mathrm{f} & =\left(\left(\mathrm{V}^{2} / 127 \mathrm{R}\right)-0.07\right) \\
& =\left(\left(45^{2} / 127 * 90\right)-0.07\right) \\
& =0.107
\end{aligned}
$$

As the value is less than 0.15 , the design is safe with a superelevation of 0.07 .

Raising of outer edges of the pavement with respect to centre line

$\mathrm{E}=(\mathrm{B} * \mathrm{e}) / 2$; where $\mathrm{B}$ is the carriageway width

$$
=(7.5 * 0.07) / 2
$$

$=0.26 \mathrm{~m}$

Extra widening at curve

$\mathrm{W}_{\mathrm{e}}=\left(\mathrm{nl}^{2} / 2 \mathrm{R}\right)+(\mathrm{V} / 9.5$ sqrt. $\mathrm{R})$ 
Assuming, $\mathrm{n}=$ no. of lanes $=2$; Wheel base of the truck, $1=6 \mathrm{~m}$

$$
\begin{aligned}
\mathrm{W}_{\mathrm{e}} & =\left(2 * 6^{2} / 2 * 90\right)+(45 / 9.5 * \text { sqrt. } 90) \\
& =0.90 \mathrm{~m}
\end{aligned}
$$

Total pavement width on curve $=7+0.9=7.9 \mathrm{~m}$

Horizontal Transition Curve

The IRC recommends the use of the spiral as transition curve in the horizontal alignment as spiral curve satisfies the requirement of ideal transition and its geometry property makes the calculation simple and easy in the field.

Calculation of length of transition curve:

(a) Length of transition curve by rate of change of centrifugal acceleration $\mathrm{L}_{\mathrm{s}}=0.0215^{*} \mathrm{~V}^{3} / \mathrm{C} * \mathrm{R}$

where $L_{s}$ is length of transition curve; $C$ is allowable rate of change of centrifugal acceleration, $\mathrm{m} / \mathrm{sec}^{3} ; \mathrm{R}$ is the radius of circular curve

$$
\begin{aligned}
\mathrm{C} & =80 /(75+\mathrm{V}) \\
& =80 /(75+45) \\
& =0.66
\end{aligned}
$$

As the value of $\mathrm{C}$ is between 0.5 and 0.8 , it is accepted for the design.

Radius of horizontal curve $=90 \mathrm{~m}$

$\mathrm{L}_{\mathrm{s}}=\left(0.0215 * 45^{3}\right) /(0.66 * 90)$

$$
=33 \mathrm{~m}
$$

(b)Length of transition curve by the rate of introduction of superelevation

Superelevation $\mathrm{e}=0.07$

Allowable rate of introduction of superelevation $=1$ in 150 (IRC recommended)

Total raise of outer edge of pavement with respect to centre line

$$
\begin{aligned}
\mathrm{E} & =\left(\mathrm{e}^{* \mathrm{~B}}\right) / 2 \\
& =(0.07 * 7.9) / 2 \\
& =0.27 \mathrm{~m} \\
\mathrm{~L}_{\mathrm{s}} & =(\mathrm{E} * \mathrm{~N}) / 2 \\
& =0.27 * 150 \\
& =40.5 \mathrm{~m}
\end{aligned}
$$

(c) Minimum value of $\mathrm{L}_{\mathrm{s}}$ as per IRC for rolling terrain $=\left(2.7 * \mathrm{~V}^{2}\right) / \mathrm{R}$

$$
\begin{aligned}
& =\left(2.7 * 45^{2}\right) / 90 \\
& =60.75 \mathrm{~m}
\end{aligned}
$$

Adopt the highest value of the three a,b,c as the design length of transition curve $=60.75 \mathrm{~m}$

Shift, $\mathrm{S}=\mathrm{L}_{\mathrm{s}}^{2} / 24 \mathrm{R}$

$$
=61^{2} /(24 * 9)=1.7 \mathrm{~m}
$$

Set-back distance

(i) For SSD

The minimum clearance or setback distance needed $\mathrm{m}=\mathrm{CD}$ and half the central angle $\alpha^{\prime} / 2=$ angle AOD

The distance $d$ between the centre line of the pavement and centerline of the inside lane may be taken as onefourth the width of pavement at curve for two lane pavement $=7.9 / 4=1.9 \mathrm{~m}$ $\alpha / 2=180 * \mathrm{~S} /(2 \pi(\mathrm{R}-\mathrm{d}))$

$$
\begin{aligned}
& =180 * 52.79 /(2 \pi(90-1.9)) \\
& =17.24 \mathrm{deg}
\end{aligned}
$$

Set back distance $\mathrm{m}^{\prime}=\mathrm{R}-(\mathrm{R}-\mathrm{d}) \cos \alpha^{\prime} / 2$

$$
=5.85 \mathrm{~m}
$$

Required clearance from the centre line to provide SSD of $52.79 \mathrm{~m}$ is $6 \mathrm{~m}$.

$$
\begin{aligned}
& \text { (ii) For OSD } \\
& \mathrm{S}=95.54 \mathrm{~m} \\
& \mathrm{~L}_{\mathrm{c}}=60.75 \mathrm{~m} \\
& \mathrm{R}=90 \mathrm{~m} \\
& \mathrm{~d}=1.9 \mathrm{~m} \\
& \alpha / 2=180^{*} \mathrm{~L}_{\mathrm{c}} /(2 \pi(\mathrm{R}-\mathrm{d}))
\end{aligned}
$$$$
=180 * 60.75 /(2 \pi(90-1.9))
$$$$
=19.75 \mathrm{deg}
$$

Set back distance $\mathrm{m}^{\prime}=\mathrm{R}-(\mathrm{R}-\mathrm{d}) \cos \alpha^{\prime} / 2+\left(\mathrm{S}-\mathrm{L}_{\mathrm{c}}\right) / 2 * \sin \alpha^{\prime} / 2$ 


$$
\begin{aligned}
& =7.08+5.87 \\
& =13 \mathrm{~m}
\end{aligned}
$$

Minimum setback distance required from the centre line of the road on the inner side of the pavement to provide an OSD of $95.54 \mathrm{~m}=13 \mathrm{~m}$

Design of vertical alignment

As per IRC specification, for Plain or Rolling terrain the ruling gradient should be 3.3\% (1 in 30); Limiting gradient should be 5\% (1 in 20); Exceptional gradient should be 6.7\% (1 in 15) and a minimum gradient of about a slope of 1 in 200 or $0.5 \%$ may be needed on inferior surfaces.

Vertical Curves-

Generally simple parabolic curve is used as summit curve instead of circular arc as it is found that it give good riding comfort and also a parabola is very easy for arithmetical manipulation for computing ordinates.

Length of summit curve

(i) For SSD

Assuming L $>$ SSD,

$$
\mathrm{L}=\mathrm{NS}^{2} /(\text { sqrt. } 2 \mathrm{H}+\text { sqrt. } 2 \mathrm{~h})^{2}
$$

Here $\mathrm{L}=$ Length of summit curve, $\mathrm{m}$

$\mathrm{S}=\mathrm{SSD}, \mathrm{m}$

$\mathrm{N}=$ deviation angle

$\mathrm{H}=$ Height of eye level of driver above roadway

$\mathrm{h}=$ height of subject above pavement

Taking gradients of ramps as ascending $4 \%$ gradient and $6 \%$ descending gradient

$$
\mathrm{n}_{1}=+4 / 100 ; \mathrm{n}_{2}=-6 / 100
$$

Deviation angle $\mathrm{N}=0.04-(-0.06)$

$$
\begin{aligned}
\mathrm{L} & =\mathrm{N} * \mathrm{~S}^{2} / 4.4 \\
& =0.1 * 52.79^{2} / 4.4 \\
& =63.33 \mathrm{~m}>52.79 \mathrm{~m} \quad \text { Assumption is } \mathrm{OK}
\end{aligned}
$$

Length of summit curve $=63.33 \mathrm{~m}$

(ii) For OSD

Assuming L $>\mathrm{OSD}$,

$$
\begin{aligned}
\mathrm{L} & =\mathrm{NS}^{2} / 9.6 \\
& =0.1 * 95.54^{2} / 9.6 \\
& =95.08 \mathrm{~m}
\end{aligned}
$$

As this value is less than OSD of $95.54 \mathrm{~m}$ so now assume $\mathrm{L}<\mathrm{OSD}$

$$
\begin{aligned}
\mathrm{L} & =2 \mathrm{~S}-(9.6 / \mathrm{N}) \\
& =2 * 95.54-(9.6 / 0.1) \\
& =95 \mathrm{~m} \text { which is less than OSD }
\end{aligned}
$$

Length of summit curve $=95 \mathrm{~m}$

Length of Valley Curves

Considering the same gradient, $\mathrm{N}=-0.1 ; \mathrm{V}=45 \mathrm{kmph}=12.5 \mathrm{mps} ; \mathrm{C}=0.6 \mathrm{~m} / \mathrm{sec}^{3}$

( $\mathrm{C}$ is change of centrifugal acceleration as per IRC recommended)

(i) Comfort condition

$$
\begin{aligned}
\mathrm{L} & =2\left(\mathrm{Nv}^{3} / \mathrm{C}\right)^{0.5} \\
& =2\left(0.1 * 12.5^{3} / 0.6\right)^{0.5} \\
& =36 \mathrm{~m}
\end{aligned}
$$

(ii) Head light Sight distance condition

$$
\begin{aligned}
& \text { If } \mathrm{L}>\mathrm{SSD} \\
& \mathrm{L}=\mathrm{N} * \mathrm{~S}^{2} /(1.5+0.035 * \mathrm{~S})
\end{aligned}
$$$$
=\left(0.1 * 52.79^{2}\right) /(1.5+0.035 * 52.79)
$$$$
=83.24 \mathrm{~m}
$$

Assumption correct. So length of valley curve $=83.24 \mathrm{~m}$

Street Lightening Spacing

Designing a Street Lighting System considering the street width $=15 \mathrm{~m}$, Mounting height $=7.5 \mathrm{~m}$, Lamp size= 6000lumen and Luminaire type II.

Average Lux $=6.0$

Ratio $=$ Pavement width/ Mounting height $=15 / 7.5=2$ 
From IRC specification, coefficient of utilization $=0.44$

Assuming a maintenance factor $=0.8$

Spacing $=($ Lamp lumen $*$ co-efficient of utilization *maintenance factor $) /($ Average Lumen $*$ Width of road $)=$ $(6000 * 0.44 * 0.8) /(6 * 151)=23.2 \mathrm{~m}$

Design of surface drainage

Design of surface drainage may be divided into 2 phases -

1. Hydrologic analysis

2. Hydraulic analysis

Hydrologic analysis

Rational formula is widely used to estimate the peak runoff water for highway drainage.

$\mathrm{Q}=\mathrm{C} * i * \mathrm{~A}_{\mathrm{d}}$

Where, $\mathrm{Q}=\operatorname{runoff}\left(\mathrm{m}^{3} / \mathrm{s}\right)$

$\mathrm{C}=$ runoff coefficient

$\mathrm{i}=$ Intensity of rainfall $(\mathrm{mm} / \mathrm{sec})$

$\mathrm{A}_{\mathrm{d}}=$ Drainage area

Considering,

$\mathrm{A}_{\mathrm{d}}=15$ hectares

Weighted value of runoff coefficient of various surfaces $=0.37$

Time of concentration $=19.33$ min (Refer from graph and table, also hydrology book S.K.Garg)

So from the graph, the value corresponding to 19.33 min duration and 25 years period, the rainfall intensity of chandikhole can be computed as $125 \mathrm{~mm} / \mathrm{hr}$

$\mathrm{i}=125 /(60 * 60)=0.0347 \mathrm{~mm} / \mathrm{sec}$

Runoff, $\mathrm{Q}=\mathrm{C} * \mathrm{i}^{*} \mathrm{~A}_{\mathrm{d}}$

$$
\begin{aligned}
& =0.371 * 0.0347 * 15 \\
& =0.193 \mathrm{~m}^{3} / \mathrm{sec}
\end{aligned}
$$

Hydraulic analysis

Cross Section

Area of cross section of flow in the drawn is given as $A=Q / V$

Assuming suitable speed of flow $=0.8 \mathrm{~m} / \mathrm{s}$ (IRC specification) $\mathrm{A}=0.193 / 0.8=0.241 \mathrm{~m}^{2}$ Assuming bottom width of drain as $0.5 \mathrm{~m}$, slope of 1 vertical to 1.5 horizontal and depth of flow as d, so top width $=(0.5+3 \mathrm{~d}) \mathrm{m}$

Area of cross section of flow in drain is given by,

$0.241=(0.5+0.5+3 \mathrm{~d}) * \mathrm{~d} / 2$

i.e. $1.5 d^{2}+0.5 d-0.241=0$

On solving, $\mathrm{d}=0.267 \mathrm{~m}$

Allowing a free board of $0.15 \mathrm{~m}$, depth of the side drain $=0.267+0.15=0.417 \mathrm{~m}$

A. Slope of drain

The longitudinal slope can be found by using Manning's Formula

$$
\begin{aligned}
& \mathrm{V}=(1 / \mathrm{n}) * \mathrm{R}^{0.67} * \mathrm{~S}^{0.5} \\
& \mathrm{~V}=0.8 \mathrm{~m} / \mathrm{s} \\
& \mathrm{n}=0.162
\end{aligned}
$$

Wetted perimeter $=\left(\right.$ sqrt. $\left.\left(\mathrm{d}^{2}+1.5 \mathrm{~d}^{2}\right)\right) * 2+\mathrm{b}=1.462 \mathrm{~m}$

$\mathrm{R}=\frac{\text { Area }}{\text { Wetted Perimeter }}=\frac{0.241}{1.462}=0.164$

$\mathrm{V}=(1 / \mathrm{n}) * \mathrm{R}^{0.67} * \mathrm{~S}^{0.5}$

$\mathrm{S}^{0.5}=\mathrm{V} * \mathrm{n} / \mathrm{R}^{0.67}$

$$
=(0.8 * 0.162) / 0.164^{0.67}
$$

$=0.0672$

$\mathrm{S}=0.00452$ i.e. 1 in 221

Therefore, provide a longitudinal slope of 1 in 220

\section{Conclusions}

It was determined that construction of Diverging Diamond Interchange would be most reasonable and beneficial for this location. A DDI is a type of interchange which is designed to increase capacity, decrease congestion and minimize new construction cost. It is different from traditional interchanges that would typically encounter when entering or existing an interstate freeway. They allow for free left turn movements, meaning that left turning vehicles will not cross in front of opposite traffic which results in reduction in travel time, fuel consumption and improved safety. It is also expected that area would draw more corporations due to innovative 
and attractive infrastructure design and therefore creating more jobs and stimulating more investment in the local community.

\section{Acknowledgement}

I would like to express my gratitude to all people behind the screen who helped us to transform an idea into real application.

I would like to express my heart-felt gratitude to my parents with whom I would not have been privileged to achieve and full fill my dreams.I profoundly thank Dr. M.R. Das, Head of Department, Civil Engineering, who has been an excellent guide and also great source of inspiration to my work.I would like to thank to my Project Co-ordinator Dr.Subrat Kumar Rout for his technical guidance, constant encouragement and support carrying out my project work.

The satisfaction and euphoria that accompany the successful completion of task would be great but in complete with the mention of the people who made it possible with the guidance and encouragement.

\section{References}

[1]. Highway engineering by S.K. Khanna and C.E.G. Justo

[2]. Hughes, Warren, Jagannathan, Ram (October 2009) "Double Crossover Diamond Interchange"

[3]. Diverging Diamond Interchange OHM advisors

[4]. Chlewicki, Gilbert (2003) "New Interchange and Intersection Designs"

[5]. Diverging Diamond Interchange locations. (Website-www.divergingdiamond.com) verified with Google Maps.

[6]. United States Patent 8,950,970; Double Crossover Merging Interchange.

[7]. Engineering Hydrology By S.K. Garg 